\title{
METHODS, ALGORITHMS, AND COMPUTER CODES FOR CALCULATION OF ELECTRON-IMPACT EXCITATION PARAMETERS
}

\author{
P. Bogdanovich, R. Kisielius, and D. Stonys \\ Institute of Theoretical Physics and Astronomy, Vilnius University, A. Goštauto 12, LT-01108 Vilnius, Lithuania \\ E-mails: pavelas.bogdanovicius@tfai.vu.lt
}

Received 20 December 2013; revised 13 March 2014; accepted 29 May 2014

\begin{abstract}
We describe the computer codes, developed at Vilnius University, for the calculation of electron-impact excitation cross sections, collision strengths, and excitation rates in the plane-wave Born approximation. These codes utilize the multireference atomic wavefunctions which are also adopted to calculate radiative transition parameters of complex many-electron ions. This leads to consistent data sets suitable in plasma modelling codes. Two versions of electron scattering codes are considered in the present work, both of them employing configuration interaction method for inclusion of correlation effects and Breit-Pauli approximation to account for relativistic effects. These versions difer only by one-electron radial orbitals, where the first one employs the nonrelativistic numerical radial orbitals, while the other version uses the quasirelativistic radial orbitals. The accuracy of produced results is assessed by comparing radiative transition and electron-impact excitation data for neutral hydrogen, helium, and lithium atoms as well as highly charged tungsten ions with theoretical and experimental data available from other sources.
\end{abstract}

Keywords: electron impact, excitation, many-electron ions

PACS: 31.15.ag, 34.80.Dp, 95.30.Ky

\section{Introduction}

In modelling both high temperature plasma (stellar atmosphere, nuclear fusion) and low temperature plasma, such as planetary nebulae, working material of spectroscopic and medical devices, one needs data on free-electron interaction with atoms and ions. For the consistency of plasma models, it is highly desirable that such data are calculated within the same approximation, using the identical multireference atomic wavefunctions, applying the same methods to include relativistic and correlation corrections as it has been done in production of spectroscopic data, such as energy levels, oscillator strengths, and radiative transition probabilities.

Over many years, original methods and computer codes designated to calculate various spectral parameters of atoms and ions have been developed in the Department of Atomic Theory, Institute of Theoretical Physics and Astronomy, Vilnius University [1],2]. Currently, these codes have been supplemented with our new codes computing electron-impact excitation parameters for ions in the plane-wave Born approximation. The main purpose of this development is to establish a consistent and complete set of data necessary for plasma spectra modelling. Such a set will be suitable for our newly developed database ADAMANT (Ap- plicable DAta of Many-electron Atom eNergies and Transitions), where the main requirement is to produce data sets within the same atomic wavefunctions base, hence, simplifying an application of these data in modelling codes. In Section 2 of the present work, for the first time we describe the implemented calculation methods. Further, in Section 3, we describe the algorithms implemented in our computer codes.

Developed methods and computer codes are equipped to calculate many-electron atoms and ions with open s-, p-, d-, and f- shells when consistent inclusion of the correlation effects is necessary. It is important to perform calculation of the electron-impact excitation parameters using an extensive configuration interaction basis in order to match them to other spectroscopic parameters, such as energy levels, transition probabilities, oscillator strengths, determined in the same approximation and similar accuracy. These codes will be employed in cases when the adaption of other more accurate theoretical methods, such as R-matrix approximation (RM) or converged close-couling approximation (CCC)), is very difficult or even impossible due to a complex atomic structure (e. g. for heavy multicharged ions). The plane-wave Born approximation to calculate the electron-impact excitation parameters was chosen as a suitable one by the developers of theAtomic Data and Analysis System the (ADAS), see [3]. ADAS 
needs the data for complex tungsten ions which cannot be determined using other approximations.

In the current work, in order to benchmark the adopted approximations and developed codes, we present the investigation of the electron-impact excitation cross sections for light atoms, namely $\mathrm{H}, \mathrm{He}$, and $\mathrm{Li}$. There is a substantial amount of atomic structure and electron-atom interaction data for these atoms, both theoretical and experimental ones. Most of them can be found in the NIST Atomic Spectra Database [4t, the NIST Electron-Impact Excitation Cross Sections Database [5], and the CCC database [6]. We choose $\mathrm{H}, \mathrm{He}$, and $\mathrm{Li}$ atoms for comparison since these are the only atoms having electron-impact excitation data in the NIST database [5] which usually contains only very reliable parameters. We have performed our calculation by employing both the non-relativistic radial orbitals and the quasirelativistic ones. Determined results are compared in Section 4. Conclusions are presented in the final Section.

\section{Description of adopted method}

The total cross section $\sigma$, describing the interaction of an incident electron having the energy $\varepsilon$ with an atom, for the excitation from the energy level $K_{0} \lambda_{0} J_{0}$ to the level $K_{1} \lambda_{1} J_{1}$ is expressed as a sum of the excitation cross sections with different ranks $\kappa$ :

$$
\begin{aligned}
& \sigma\left(K_{0} \lambda_{0} J_{0}, K_{1} \lambda_{1} J_{1}, \varepsilon\right)= \\
& \sum_{\kappa} \sigma_{\kappa}\left(K_{0} \lambda_{0} J_{0}, K_{1} \lambda_{1} J_{1}, \varepsilon\right) .
\end{aligned}
$$

Here $K$ denotes electronic configuration, $\lambda$ denotes level number, $J$ stands for the total angular momentum, and $\varepsilon$ is the energy of incident electron. Contrary to the case of radiative transitions, $\sigma_{\kappa}$ does not contain the fine-structure parameter $\alpha$, and the summation in (1) must be performed over all possible ranks $\kappa$. This summation must be performed over even or odd $\kappa$ values, depending on the parity of the initial and final levels, including $\kappa=0$, if the excitation process does not change their parity. The rank $\kappa$ must satisfy the triangular condition with the even perimeter $\left(J_{0}, \kappa, J_{1}\right)$.

The excitation cross section $\sigma_{\kappa}$ of any rank $\kappa$ is expressed using the matrix element $\mathcal{S}_{\kappa}$ of electron-impact excitation operator:

$$
\begin{aligned}
& \sigma_{\kappa}\left(K_{0} \lambda_{0} J_{0}, K_{1} \lambda_{1} J_{1}, \varepsilon\right)=\frac{4 \pi a_{0}^{2}}{\varepsilon}\left(2 J_{1}+1\right) \\
& \int_{k_{0}-k}^{k_{0}+k}\left|\mathcal{S}_{\kappa}\left(K_{0} \lambda_{0} J_{0}, K_{1} \lambda_{1} J_{1}, q\right)\right|^{2} \frac{\mathrm{d} q}{q^{3}} .
\end{aligned}
$$

Here $a_{0}=0.5291772 \times 10^{-10} \mathrm{~m}$ is atomic length unit. We must underline that all our calculations are per- formed in the system of atomic units. Integration is performed over the difference of the electron momenta; $k_{0}$ is the momentum of an incident electron, and $k$ is the momentum of an outgoing electron.

Our developed methods and computer codes determine cross sections for transitions between different energy levels by employing multiconfigurational multi-term wavefunctions in LSJ-coupling:

$$
\begin{aligned}
& \Psi\left(K_{0} \lambda_{0} J_{0} \mid x\right)= \\
& \sum_{K T L S} a\left(K_{0} \lambda_{0} J_{0}, K T L S J_{0}\right) \Psi\left(K T L S J_{0} \mid x\right) .
\end{aligned}
$$

Here TLS denote the intermediate and final orbital and spin-angular momenta for the pure LSJ-coupling wavefunction, and $x$ denotes coordinates of all electrons of the wavefunction $\Psi$. In this case, the matrix element of the electron-impact excitation operator is expressed by relation

$$
\begin{aligned}
& \mathcal{S}_{K}\left(K_{0} \lambda_{0} J_{0}, K_{1} \lambda_{1} J_{1}, q\right)= \\
& \sum_{K T L S, K^{\prime} T L^{\prime}} a\left(K_{0} \lambda_{0} J_{0}, K T L S J_{0}\right) \\
& \times \mathcal{S}_{K}\left(K T L S J_{0}, K^{\prime} T^{\prime} L^{\prime} S J_{1}, q\right) a\left(K^{\prime} T^{\prime} L^{\prime} S J_{1}, K_{1} \lambda_{1} J_{1}\right) .
\end{aligned}
$$

In this approximation, the excitation process does not change the term multiplicity $S$. The matrix elements for the excitation process in pure LSJ-coupling can be described by a product

$$
\begin{aligned}
& \mathcal{S}_{\kappa}\left(K T L S J_{0}, K^{\prime} T^{\prime} L^{\prime} S J_{1}, q\right)= \\
& Q_{\kappa}\left(K T L S, K^{\prime} T^{\prime} L^{\prime} S\right) W_{\kappa}\left(J_{0}, J_{1}\right) R_{\kappa}\left(n_{\mathrm{i}} \ell_{\mathrm{i}}, n_{\mathrm{f}} \ell_{\mathrm{f}}, q\right) .
\end{aligned}
$$

Here $Q_{\kappa}\left(K T L S, K^{\prime} T^{\prime} L^{\prime} S\right)$ is an angular integral for the matrix element of the electric multipole transition operator of the rank $\kappa$, which can be determined using the code 服 developed for the calculation of the radiative transition matrix elements. Therefore, the rank $\kappa$ must satisfy the triangular condition with the even perimeter $\left(L_{0}, \kappa, L_{1}\right)$. The expression for $Q_{\kappa}$ also includes sub-matrix elements of the spherical function, consequently, an additional triangular condition with the even parameter $\left(\ell_{\mathrm{i}}, \kappa, \ell_{\mathrm{f}}\right)$ arises, where $\ell_{\mathrm{i}}$ and $\ell_{\mathrm{f}}$ are the orbital momenta of the excited electron before and after collision. The coefficient describing the bounding of the total orbital momentum $L$ and the total spin $S$ into the total angular momentum $J$ is the same as in calculation of the radiative transition matrix element:

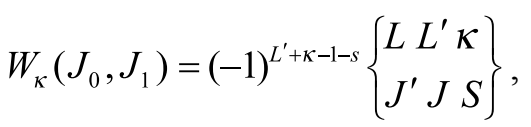


where the element in curly brackets denotes the $6 j$ coeffcient. $R_{\kappa}\left(n_{\mathrm{i}} \ell_{\mathrm{i}}, n_{\mathrm{f}} \ell_{\mathrm{f}} q\right)$ is a radial integral:

$$
\begin{aligned}
& R_{\kappa}\left(n_{\mathrm{i}} \ell_{\mathrm{i}}, n_{\mathrm{f}} \ell_{\mathrm{f}}, q\right)= \\
& \int_{0}^{\infty} P\left(n_{\mathrm{i}} \ell_{\mathrm{i}} \mid r\right) P\left(n_{\mathrm{f}} \ell_{\mathrm{f}} \mid r\right)\left[j_{\kappa}(q r)-\delta_{\kappa 0}\right] \mathrm{d} r,
\end{aligned}
$$

where $P(n \ell \mid r)$ denotes a one-electron radial orbital of the initial and the final state of an electron, $\delta_{\kappa 0}$ is a Kronecker delta function, and $j_{\kappa}(q r)$ is a spherical Bessel function [8]:

$$
j_{\kappa}(q r)=\left(\frac{\pi}{2 q r}\right)^{1 / 2} J_{\kappa+1 / 2}(q r) .
$$

Finally, we can define an expression for the total electron-impact excitation cross section:

$$
\begin{aligned}
& \sigma\left(K_{0} \lambda_{0} J_{0}, K_{1} \lambda_{1} J_{1}, \varepsilon\right)= \\
& \frac{4 \pi a_{0}^{2}}{\varepsilon}\left(2 J_{1}+1\right) \sum_{\kappa} \int_{k_{\sigma}-k}^{k_{0}+k} \sum_{K T L S, K T^{\prime} L^{\prime}}\left[a\left(K_{0} \lambda_{0} J_{0}, K T L S J_{0}\right)\right. \\
& \times Q_{\kappa}\left(K T L S, K^{\prime} T^{\prime} L^{\prime} S\right) W_{\kappa}\left(J_{0}, J_{1}\right) \\
& \times \int_{0}^{\infty} P\left(n_{\mathrm{i}} \ell_{\mathrm{i}} \mid r\right) P\left(n_{\mathrm{f}} \ell_{\mathrm{f}} \mid r\right)\left[j_{\kappa}(q r)-\delta_{\kappa 0}\right] \mathrm{d} r \\
& \times a\left(K^{\prime} T^{\prime} L^{\prime} S J_{1}, K_{1} \lambda_{1} L S\right]^{2} \frac{\mathrm{d} q}{q^{3}} .
\end{aligned}
$$

From (9) one can see that the expression for the electron-impact excitation cross section has a similar structure and analogous angular integrals compared to calculation of the radiative transition probabilities. Nevertheless, the radial part in the electron-impact excitation cross section expression is much more complex. There is a double integral and sum over all possible ranks $\kappa$ instead of one single integral. Moreover, calculations must be performed for various energies of the incident electron $\varepsilon$. These energies are usually expressed using the excitation threshold energies, which are determined as a difference between the energies of the final and initial levels. Consequently, there is a different set of free-electron energies for each excitation channel. Therefore, a special attention should be paid in order to simplify and speed up calculation of the radial integrals for the excitation cross sections.

\section{Calculation algorithm}

At first, we determine all necessary angular integrals $Q_{\kappa}\left(K T L S, K^{\prime} T\right.$ 'L'S) for the matrix element of the transition operator. In order to avoid repetitive calculations of the radial integrals with close values of the parameter $q$, we exploit interpolation of radial integrals. For this purpose, we determine the minimum and maxi- mum values of $q$ from the initial information about the investigated excitation. Within these limits, a grid of $1001 q$-values is generated. Since the functions in the calculated integral are more sensitive at the lower parameter values, this grid of $q$-values is formed using a logarithmic step. Next, a two-dimensional grid of $q$ and the radial variable $r$ products is generated. A grid for the Bessel function (8) is determined according to the grid of the parameter $q \cdot r$ for all necessary rank $\kappa$ values, starting with $\kappa=0$. After the Bessel function grid is generated, all the possible integrals $($ ) are determined for given $q$ values. These computations do not require too much time even if the quantities of the parameter $q$ and radial variable $r$ values are large.

After the $R_{\kappa}$ grid is determined, electron-impact excitation cross sections can be produced. In most cases, the incident electron energies $\varepsilon$ are introduced in the excitation threshold units. Nevertheless, there is a possibility in our code to define a different energy grid. A grid of the parameter $q$ is determined for each incident electron energy in order to perform integration in (2). As in the previous case, this grid has a logarithmic step. We have performed a computational experiment and have determined that a desirable accuracy can be achieved if the Simpson's rule [9] is applied for the integral when a number of points is as low as 25 . The integrals $R_{\kappa}\left(n_{\mathrm{i}} \ell_{\mathrm{i}}, n_{\mathrm{f}} \ell_{\mathrm{p}} q\right)$, which are necessary for calculation of the electron-impact excitation matrix elements in (5), are determined by interpolating their values according to the previously generated values. Only the nearest four points are required for this interpolation. Integration over the parameter $q$ is performed for the determined matrix element. Further, the calculated $\sigma_{\kappa}\left(K_{0} \lambda_{0} J_{0}, K_{1} \lambda_{1} J_{1}, \varepsilon\right)$ values are summed over all possible ranks $\kappa$ as in (1), and the total electron-impact excitation cross section is determined. We are performing parallel computing for the cross sections of different ranks $\kappa$ in order to accelerate production of results.

The above described calculation method is realized in two computer codes. One of these codes exploits the non-relativistic Hartree-Fock (HF) radial orbitals. Another one employs the numerical quasirelativistic $(\mathrm{QR})$ radial orbitals. The performance of our new codes was tested on complex heavy ions, such as $\mathrm{Hf}-\mathrm{Hf}^{3+}, \mathrm{Ta}^{+}-\mathrm{Ta}^{4+}, \mathrm{W}^{2+}-\mathrm{W}^{5+}$, and $\mathrm{Re}^{3+}-\mathrm{Re}^{6+}$. Such complex systems require to deal correctly with both relativistic corrections and correlation effects. Unfortunately, there are no reliable experimental or theoretical data for such complex systems published so far. Furthermore, in order to benchmark these newly developed codes, we have performed calculation of the electron-impact excitation cross sections for three light neutral atoms, namely, hydrogen, helium and lithium. Some data for the $\mathrm{W}^{45+}$ ion were also calculated and 
compared with calculations performed using a more sophisticated R-matrix method in the next section. Finally, we demonstrate abilities of our computer codes by presenting the electron-impact excitation cross sections for several low-ionization stages of tungsten ions.

\section{Results and discussions}

The NIST database [5] contains the total electron-impact cross sections for the transitions from the ground configuration with one level to an excited configuration rather than to separate levels. Our computer codes are designed to determine cross sections for the transitions between the individual levels of many-electron atoms and ions (9). Therefore, the results determined in the present work were summed over all levels of the final configuration. In the general case, a cross section averaging is performed by applying the expression:

$$
\begin{aligned}
& \sigma\left(K_{0}, K_{1}, \varepsilon\right)= \\
& \frac{\sum \lambda_{0 i} J_{0 i}, \lambda_{1 j} J_{1 j}}{}\left(2 J_{0 i}+1\right) \sigma\left(K_{0} \lambda_{0 i} J_{0 i}, K_{1} \lambda_{1 j} J_{1 j}, \varepsilon\right) .
\end{aligned}
$$

The most of the data for comparison with our results are taken from [10]. The electron-impact excitation cross sections in that work are scaled (BE-scaling) according to a method developed for neutral atoms in [1]:

$$
\sigma_{B E}\left(K_{0}, K_{1}, \varepsilon\right)=\frac{\varepsilon}{\varepsilon+B+E} \sigma\left(K_{0}, K_{1}, \varepsilon\right) .
$$

Here $B$ is the ionization energy of the initial level, $E$ is the transition energy. Such a scaling significantly alters cross section values, particularly those at the energies close to the excitation threshold. This leads to a substantially better agreement between theoretical results and experimental data. Since the scaled data for cross sections are presented in [10], we utilize the $B E$-scaling for all our results in the current work. Likewise in [10], we utilize the $B$ values from [5], and these values agree favourably with our theoretical results. For the transition energy $E$, we have utilized our $a b$ initio energy values. The electron-impact excitation cross sections in [10] were computed using the one-configuration Dirac-Fock approximation. Therefore, in order to improve the accuracy of calculated data, the authors introduced an additional $f$-scaling:

$$
\sigma_{B E, f}\left(K_{0}, K_{1}, \varepsilon\right)=\frac{f_{\mathrm{ac}}}{f_{\mathrm{sc}}} \sigma_{B E}\left(K_{0}, K_{1}, \varepsilon\right) .
$$

where the ratio of oscillator strengths was applied. Here $f_{\text {sc }}$ is a theoretical (one-configuration approxima- tion) oscillator strength, and $f_{\mathrm{ac}}$ is a high-accuracy oscillator strength from [4]. Since the multiconfiguration approximation is employed in the present work, the $f$ scaling is not performed for production of our results.

For comparison with the results from [10], we introduce a mean-square deviation $M S D$ defined as

$$
\begin{aligned}
& M S D=\sqrt{\frac{1}{N} \sum_{n=1}^{N}\left[\frac{\sigma_{B E, f}\left(K_{0}, K_{1}, \varepsilon_{n}\right)-\sigma_{B E}\left(K_{0}, K_{1}, \varepsilon_{n}\right)}{\sigma_{B E, f}\left(K_{0}, K_{1}, \varepsilon_{n}\right)}\right]^{2}} \\
& \times 100 \%
\end{aligned}
$$

where $\sigma_{B E, f}\left(K_{0}, K_{1}, \varepsilon_{n}\right)$ stands for the data from [10], $\sigma_{B E}\left(\mathrm{~K}_{0}, K_{1}, \varepsilon_{n}\right)$ is our calculated cross section results. Summations were performed for all electron energies $\varepsilon_{n}$ presented in the NIST database.

\subsection{Excitation of hydrogen atom}

We have investigated the electron-impact excitation of the 1 s electron to the $2 p, 3 p$, and $4 p$ states. As one can expect, an agreement with data from [10] is excellent for all three transitions within the complete energy range. Both the $\mathrm{HF}$ and the QR results display $M S D=0.22 \%$ for these three transitions, and our results are slightly lower than the data from [10]. The deviations for the $1 s-2 p$ excitation are larger at the beginning of the investigated energy range, where the deviations are approximately $0.43 \%$ at $\varepsilon=11 \mathrm{eV}$, and at the end of the presented energy range, where the deviations are roughly $0.82 \%$ at $\varepsilon=3000 \mathrm{eV}$. In the middle of the energy range, the deviations do not exceed $0.12 \%$. A completely similar situation is for the excitation to the $3 p$ state. For excitation to the $4 p$ state, the deviations at the low and at the high energy end increase, but this increase does not change MSD noticeably.

In Table 1 we present the electron-impact excitation cross sections of a hydrogen atom for the cases where it is possible to make comparison with the data produced by several authors. For our data, we present only the HF results because, as one can expect, the difference between our HF and QR results appears only in the fifth or sixth significant digit. We present the theoretical results determined using the method [6] and the experimental data from [12]. It is not unusual that our data agree better with the data from [10] rather than with those from [6]. Their agreement with the experimental data from [12] is within error limits.

\subsection{Excitation of helium atom}

We determined the cross sections of electron-impact excitation from the $1 \mathrm{~s}$ shell to the $2 \mathrm{p}$ and $3 \mathrm{p}$ shells. Our 
Table 1. The electron-impact excitation cross sections $\sigma$ (in $10^{-17} \mathrm{~cm}^{2}$ ) for $\mathrm{H}$ atom at various incident electron energies $\varepsilon$.

\begin{tabular}{|c|c|c|c|c|}
\hline$\varepsilon(\mathrm{eV})$ & $\mathrm{HF}$ & $B E, f[10]$ & CCC [6] & $\operatorname{Exp}[12]$ \\
\hline \multicolumn{5}{|c|}{$1 s-2 p$} \\
\hline 14 & 3.506 & 3.512 & 3.849 & \\
\hline 15 & 3.920 & 3.926 & 4.021 & 4.8 \\
\hline 20 & 5.272 & 5.278 & 5.163 & 5.7 \\
\hline 30 & 6.312 & 6.319 & 6.187 & 6.4 \\
\hline 40 & 6.524 & 6.532 & & 6.7 \\
\hline 45 & 6.506 & 6.513 & 6.499 & \\
\hline 70 & 6.025 & 6.032 & 6.142 & \\
\hline 100 & 5.330 & 5.337 & 5.485 & \\
\hline 150 & 4.417 & 4.423 & 4.582 & \\
\hline 200 & 3.772 & 3.777 & 3.912 & \\
\hline 500 & 2.076 & 2.081 & 2.126 & \\
\hline 1000 & 1.242 & 1.246 & 1.261 & \\
\hline \multicolumn{5}{|c|}{$1 s-3 p$} \\
\hline 14 & 0.437 & 0.438 & 0.564 & \\
\hline 15 & 0.536 & 0.537 & 0.587 & \\
\hline 20 & 0.827 & 0.828 & 0.752 & \\
\hline 30 & 1.039 & 1.040 & 0.960 & \\
\hline 45 & 1.086 & 1.087 & 1.024 & \\
\hline 70 & 1.010 & 1.012 & 1.014 & \\
\hline 100 & 0.895 & 0.896 & 0.899 & \\
\hline 150 & 0.741 & 0.742 & 0.761 & \\
\hline 200 & 0.632 & 0.633 & 0.652 & \\
\hline 500 & 0.346 & 0.347 & 0.355 & \\
\hline \multicolumn{5}{|c|}{$1 s-4 p$} \\
\hline 14 & 0.127 & 0.127 & 0.203 & \\
\hline 15 & 0.169 & 0.170 & 0.209 & \\
\hline 20 & 0.284 & 0.284 & 0.242 & \\
\hline 30 & 0.364 & 0.364 & 0.325 & \\
\hline 45 & 0.382 & 0.383 & 0.352 & \\
\hline 70 & 0.357 & 0.357 & 0.355 & \\
\hline 100 & 0.316 & 0.316 & 0.315 & \\
\hline 150 & 0.262 & 0.262 & 0.268 & \\
\hline 200 & 0.223 & 0.223 & 0.230 & \\
\hline 500 & 0.122 & 0.122 & 0.125 & \\
\hline
\end{tabular}

HF results were obtained in the following way. First of all, the Hartree-Fock equations were solved for the $1 \mathrm{~s} 2 \mathrm{~s}$ configuration of a helium atom. At the next step, the equations for the $2 \mathrm{p}, 3 \mathrm{~s}$, and $3 \mathrm{p}$ electrons were solved in a potential of the frozen 1 s electron. The determined radial orbital basis was complemented with the transformed radial orbitals (TRO) [2, 13, which described virtual electron excitations and had the principal quantum number values $4 \leq n \leq 9$ and all possible values of the orbital momentum $\ell$. Consistent with our other calculations, we employed the same radial orbital basis both for the even-parity and odd-parity configurations. Therefore, we can avoid problems related to the non-orthogonality of radial orbitals.

The correlation effects are included within the configuration interaction (CI) approach. We selected admixed configurations which had averaged weights, calculated in the second order of perturbation theory [12], larger than $10^{-10}$ in the wavefunction expansions of the adjusted configurations $1 \mathrm{~s} 2 \mathrm{~s}, 1 \mathrm{~s} 2 \mathrm{p}$, and $1 \mathrm{~s} 3 \mathrm{p}$ by applying the method described in [14, 15]. We can adopt such a minute selection criteria, because our investigated configurations have only two electrons. Therefore, the constructed Hamiltonian matrices are relatively small. We apply Breit-Pauli approximation to include relativistic effects. Furthermore, the parameters of radiative transitions and electron-impact excitations are calculated after the eigenvalues and the eigenfunctions are determined. Our QR+CI approximation results are obtained in a very similar way, but this time the quasirelativistic equations [16-18] are solved instead of Hartree-Fock equations in order to determine the one-electron radial orbitals.

The investigated energy levels and their radiative dipole emission transition probabilities to the ground level are given in Table 2. We present only those levels which can be excited by electron impact from the ground level via the dipole transitions. For the He atom, our calculated results are compared with those from the NIST database. Those data were determined using high-accuracy calculations for the helium isotopes [19. It is evident from Table 2 that our theoretical level energies agree very well with NIST data. The deviations reach only a few one-tenths of $\mathrm{cm}^{-1}$. Although the relativistic effects for the helium atom are small, our $\mathrm{QR}+\mathrm{CI}$ calculations give more accurate energy level values. Similar high accuracy is evident for the emission transition probabilities when they are compared with the data from compilation [20]. The accuracy of

Table 2. Energy levels $E$ and radiative transition probabilities $A$ in $\mathrm{He}$.

\begin{tabular}{c|ccccccc}
\hline Level & \multicolumn{3}{c|}{$E\left(\mathrm{~cm}^{-1}\right)$} & \multicolumn{3}{c}{$A\left(\mathrm{~s}^{-1}\right)$} \\
\hline & {$[19]$} & $\mathrm{HF}+\mathrm{CI}$ & $\mathrm{QR}+\mathrm{CI}$ & {$[20]$} & $\mathrm{HF}+\mathrm{CI}$ & $\mathrm{QR}+\mathrm{CI}$ \\
\hline $1 \mathrm{~s} 2 \mathrm{p}^{3} \mathrm{P}_{1}$ & 169087 & 169031 & 169106 & $1.764 \mathrm{E}+2$ & $1.586 \mathrm{E}+2$ & $1.714 \mathrm{E}+2$ \\
\hline $1 \mathrm{~s} 2 \mathrm{p}^{1} \mathrm{P}_{1}$ & 171135 & 171078 & 171140 & $1.799 \mathrm{E}+9$ & $1.794 \mathrm{E}+9$ & $1.826 \mathrm{E}+9$ \\
\hline $1 \mathrm{~s} 3 \mathrm{p}^{3} \mathrm{P}_{1}$ & 185565 & 185513 & 185573 & & $3.093 \mathrm{E}+1$ & $3.312 \mathrm{E}+1$ \\
\hline $1 \mathrm{~s} 3 \mathrm{p}{ }^{1} \mathrm{P}_{1}$ & 186209 & 186160 & 186255 & $5.663 \mathrm{E}+8$ & $5.604 \mathrm{E}+8$ & $5.637 \mathrm{E}+8$ \\
\hline
\end{tabular}


the $\mathrm{QR}+\mathrm{CI}$ results is fine even for the intercombination transition $1 \mathrm{~s} 2 \mathrm{p}^{3} \mathrm{P}_{1}-1 \mathrm{~s}^{2}{ }^{1} \mathrm{~S}_{0}$.

Our cross sections agree well with the data from [10] for the 1s-2p excitation. Some larger deviations, reaching a few percent, are noticeable only for the low incident electron energies $\varepsilon$. Otherwise, these deviations are significantly lower than $1 \%$. Consequently, the mean-square deviations from all data contained in the NIST database [10] are $1.2 \%$ for the $\mathrm{HF}+\mathrm{CI}$ approximation, and $M S D=2.6 \%$ for the $\mathrm{QR}+\mathrm{CI}$ approximation. The larger $M S D$ value for the quasirelativistic case is caused by more than two times larger deviations, compared to the $\mathrm{HF}+\mathrm{CI}$ approximation, at low electron energies $(\varepsilon<50 \mathrm{eV})$. The deviations from the compiled data [10] both for the QR+CI and for the $\mathrm{HF}+\mathrm{CI}$ results are of similar size at higher electron energies.

We compare our results with the data from other authors in Table 3. As in Table 1, we display only those electron energies for which there are data obtained using different methods. Such are the theoretical results from [6, 21], the experimental data from [2123], and the recommended values (RV) from [24]. One can see from Table 3 that our results are closer to those from [10] than to other theoretical data. This can be explained by the fact that we adopt the same scaling procedure (11) as in [10]. Unfortunately, we cannot achieve close agreement to the recommended values (RV) [24], especially at low electron energies.

For the 1s-3p excitation, our results agree with those from [10] slightly worse compared to the $1 \mathrm{~s}-2 \mathrm{p}$ excitation results. Here $M S D=3.7 \%$ in the HF approach, and $M S D=4.2 \%$ in the quasirelativistic approach. It is interesting that agreement for this transition is better at lower energies, but it exceeds $4 \%$ and $5 \%$, correspondingly, at high electron energies. Our $\mathrm{HF}+\mathrm{CI}$ cross section values are slightly larger than those from [10], whereas the $\mathrm{QR}+\mathrm{CI}$ data are slightly smaller at low energies, but they become larger at higher electron energies. The electron-impact excitation cross sections are tabulated in Table 4, where we present the theoretical data (CCC) from [6], the experimental data from [22, 23], and the recommended values from [25]. The fact that our calculated values are larger than those from [10 brings them closer to the recommended data from [25].

\subsection{Excitation of lithium atom}

For the lithium atom, we investigated the excitation of the 2 s electron to the 2 pand $3 p$ shells. Calculations were performed in the following way. First of all, the HartreeFock equations were solved for the $1 s^{2} 2$ s configuration.

Table 3. The $1 \mathrm{~s}-2 \mathrm{p}$ electron-impact excitation cross sections $\sigma\left(\right.$ in $\left.10^{-18} \mathrm{~cm}^{2}\right)$ for He atom at various incident electron energies $\varepsilon$.

\begin{tabular}{|c|c|c|c|c|c|c|c|c|c|}
\hline \multirow{2}{*}{$\varepsilon(\mathrm{eV})$} & \multirow{2}{*}{$\mathrm{HF}+\mathrm{CI}$} & \multirow{2}{*}{$\mathrm{QR}+\mathrm{CI}$} & \multirow{2}{*}{$\begin{array}{c}B E, f \\
{[10]}\end{array}$} & \multicolumn{2}{|c|}{ CСC } & \multicolumn{3}{|c|}{ Exp } & \multirow{2}{*}{$\begin{array}{l}\text { RV } \\
{[24]}\end{array}$} \\
\hline & & & & {$[6]$} & [21] & [22] & [23] & {$[21]$} & \\
\hline 25 & 2.851 & 2.733 & 2.933 & 2.23 & & & 1.165 & & 1.2 \\
\hline 30 & 4.566 & 4.440 & 4.669 & 3.89 & & 3.75 & 3.408 & & 3.7 \\
\hline 35 & 5.770 & 5.664 & 5.875 & & & 5.43 & & & \\
\hline 50 & 7.806 & 7.775 & 7.903 & 8.19 & & 8.20 & 8.370 & & 8.5 \\
\hline 60 & 8.452 & 8.455 & 8.542 & & & 9.52 & 9.240 & & 9.5 \\
\hline 70 & 8.799 & 8.827 & 8.883 & & & 9.77 & 9.660 & & 10.0 \\
\hline 80 & 8.965 & 9.009 & 9.043 & 10.60 & & 10.15 & 9.810 & & 10.2 \\
\hline 90 & 9.014 & 9.071 & 9.088 & & & 10.15 & 9.820 & & 10.2 \\
\hline 100 & 8.989 & 9.055 & 9.060 & 10.87 & & 10.10 & 9.740 & & 10.1 \\
\hline 120 & 8.812 & 8.889 & 8.876 & & & 9.63 & & & \\
\hline 150 & 8.406 & 8.490 & 8.462 & & & 9.18 & 8.780 & & 9.2 \\
\hline 180 & 7.961 & 8.047 & 8.012 & & & 8.81 & & & \\
\hline 200 & 7.670 & 7.756 & 7.718 & 9.05 & 8.97 & 8.30 & 7.747 & 9.2 & 8.1 \\
\hline 250 & 7.004 & 7.087 & 7.046 & & & 7.63 & & & \\
\hline 300 & 6.433 & 6.512 & 6.471 & & & 6.95 & & & \\
\hline 350 & 5.947 & 6.022 & 5.982 & & & 6.41 & & & \\
\hline 400 & 5.532 & 5.603 & 5.564 & & & 5.94 & & & \\
\hline 500 & 4.862 & 4.926 & 4.890 & 5.54 & 5.54 & 5.07 & 4.579 & 5.2 & \\
\hline 900 & 3.330 & 3.376 & 3.350 & 3.70 & & & & & \\
\hline 1000 & 3.096 & 3.139 & 3.116 & & & 3.14 & 2.903 & & \\
\hline 1500 & 2.316 & 2.349 & 2.333 & & & 2.34 & & & \\
\hline 2000 & 1.869 & 1.896 & 1.885 & & & 1.85 & 1.747 & & \\
\hline
\end{tabular}


Table 4. The $1 \mathrm{~s}-3 \mathrm{p}$ electron-impact excitation cross sections $\left(\right.$ in $10^{-18} \mathrm{~cm}^{2}$ ) for He atom at various incident electron energies $\varepsilon$.

\begin{tabular}{|c|c|c|c|c|c|c|c|}
\hline \multirow{2}{*}{$\varepsilon(\mathrm{eV})$} & \multirow{2}{*}{$\mathrm{HF}+\mathrm{CI}$} & \multirow{2}{*}{$\mathrm{QR}+\mathrm{CI}$} & \multirow{2}{*}{$B E, f[10]$} & \multirow{2}{*}{ CCC [6] } & \multicolumn{2}{|c|}{ Exp } & \multirow{2}{*}{$\mathrm{RV}$ [25] } \\
\hline & & & & & [22] & [23] & \\
\hline 25 & 0.509 & 0.494 & 0.498 & 0.40 & & & \\
\hline 30 & 1.028 & 0.992 & 1.002 & 0.75 & 0.74 & 0.582 & \\
\hline 35 & 1.366 & 1.313 & 1.329 & & 1.11 & & \\
\hline 40 & 1.611 & 1.548 & 1.565 & 1.40 & 1.38 & 1.400 & \\
\hline 45 & 1.793 & 1.726 & 1.740 & & 1.66 & & \\
\hline 50 & 1.930 & 1.863 & 1.871 & 1.88 & 1.84 & 2.166 & \\
\hline 60 & 2.112 & 2.052 & 2.043 & & 2.16 & 2.098 & \\
\hline 70 & 2.214 & 2.165 & 2.138 & & 2.34 & 2.216 & \\
\hline 80 & 2.266 & 2.228 & 2.185 & 2.46 & 2.43 & 2.265 & \\
\hline 90 & 2.287 & 2.259 & 2.202 & & 2.45 & 2.274 & \\
\hline 100 & 2.288 & 2.267 & 2.199 & 2.59 & 2.44 & 2.258 & \\
\hline 120 & 2.252 & 2.245 & 2.161 & & 2.41 & & \\
\hline 150 & 2.156 & 2.162 & 2.066 & & 2.26 & 2.041 & \\
\hline 180 & 2.046 & 2.060 & 1.959 & & 2.20 & & \\
\hline 200 & 1.973 & 1.990 & 1.888 & 2.23 & 2.08 & 1.805 & 2.08 \\
\hline 250 & 1.804 & 1.825 & 1.726 & & 1.88 & & \\
\hline 300 & 1.658 & 1.680 & 1.587 & & 1.77 & & \\
\hline 350 & 1.532 & 1.554 & 1.468 & & 1.63 & & \\
\hline 400 & 1.425 & 1.447 & 1.365 & & 1.51 & & \\
\hline 500 & 1.251 & 1.272 & 1.201 & 1.37 & 1.29 & 1.086 & 1.29 \\
\hline 900 & 0.854 & 0.868 & 0.823 & 0.92 & & & \\
\hline 1000 & 0.793 & 0.807 & 0.766 & & 0.79 & 0.691 & \\
\hline 1500 & 0.592 & 0.602 & 0.573 & & 0.59 & & \\
\hline 2000 & 0.476 & 0.484 & 0.463 & & 0.47 & 0.417 & \\
\hline
\end{tabular}

Afterward, the equations for the $2 \mathrm{p}, 3 \mathrm{~s}, 3 \mathrm{p}$, and $3 \mathrm{~d}$ electrons were solved in a frozen-core potential. This basis of radial orbitals was complemented with the TRO describing virtual electron excitations for the principal quantum number $4 \leq n \leq 11$ and for all possible values of the orbital quantum number $\ell$.

We selected all admixed configurations which have their averaged weights [12] larger than $10^{-15}$ in the adjusted configurations $1 s^{2} 2 s, 1 s^{2} 2 p$, and $1 s^{2} 3 p$. Calculations in the quasirelativistic approximation were performed in a completely analogous way. Such an extension of the TRO basis and the reduction of the configuration selection parameter down to $10^{-15}$, compared to the calculation of $\mathrm{He}$ atoms described in Sec. 4.2, was necessary in order to ensure the convergence of the $3 p-2 s$ transition probability. The determined energy levels and the transition probabilities $A$ are presented in Table 5. One can see that agreement of the energy level values with data from the NIST database is rather good. Agreement of the $2 \mathrm{p}-2 \mathrm{~s}$ transition probability values with the compilation data from [20] is fine, too. For the $3 p-2 s$ transition, we cannot achieve such an agreement, and the discrepancy of our data is approximately $6 \%$.

The cross sections for the electron-impact excitation of the $2 s-2 p$ transition are presented in Table 6.

Table 5. Energy levels $E$ and radiative transition probabilities $A$ of lithium atom.

\begin{tabular}{c|c|c|c|c|c|c}
\hline \multirow{2}{*}{ Level } & \multicolumn{3}{|c|}{$E\left(\mathrm{~cm}^{-1}\right)$} & \multicolumn{3}{c}{$A\left(\mathrm{~s}^{-1}\right)$} \\
\cline { 2 - 7 } & NIST [4] & HF+CI & QR+CI & NIST $[20]$ & HF+CI & QR+CI \\
\hline $2 \mathrm{p}^{2} \mathrm{P}_{1 / 2}$ & 14904 & 14923 & 14900 & $3.689 \mathrm{E}+7$ & $3.719 \mathrm{E}+7$ & $3.694 \mathrm{E}+7$ \\
\hline $2 \mathrm{p}^{2} \mathrm{P}_{3 / 2}$ & 14904 & 14923 & 14900 & $3.689 \mathrm{E}+7$ & $3.719 \mathrm{E}+7$ & $3.694 \mathrm{E}+7$ \\
\hline $3 \mathrm{p}^{2} \mathrm{P}_{1 / 2}$ & 30925 & 30924 & 30915 & $1.002 \mathrm{E}+6$ & $0.943 \mathrm{E}+6$ & $0.945 \mathrm{E}+6$ \\
\hline $3 \mathrm{p}^{2} \mathrm{P}_{3 / 2}$ & 30925 & 30924 & 30915 & $1.002 \mathrm{E}+6$ & $0.943 \mathrm{E}+6$ & $0.945 \mathrm{E}+6$ \\
\hline
\end{tabular}


Table 6. The 2s-2p electron-impact excitation cross sections $\sigma\left(\right.$ in $\left.10^{-16} \mathrm{~cm}^{2}\right)$ for Li atom at various incident electron energies $\varepsilon$.

\begin{tabular}{|c|c|c|c|c|c|c|c|}
\hline \multirow{2}{*}{$\varepsilon(\mathrm{eV})$} & \multirow{2}{*}{$\mathrm{HF}+\mathrm{CI}$} & \multirow{2}{*}{$\mathrm{QR}+\mathrm{CI}$} & \multirow{2}{*}{$B E, f[10]$} & \multicolumn{3}{|c|}{$\operatorname{Exp}$} & \multirow{2}{*}{ CCC [29] } \\
\hline & & & & {$[26]$} & [27] & [28] & \\
\hline 2.1 & 18.459 & 18.618 & 18.374 & & 13.020 & & \\
\hline 2.3 & 23.744 & 23.884 & 23.591 & & 17.595 & & \\
\hline 2.7 & 30.236 & 30.360 & 30.017 & & 26.920 & & \\
\hline 3.5 & 36.959 & 37.065 & 36.691 & & 35.717 & & \\
\hline 4.0 & 39.258 & 39.356 & 38.978 & & 38.796 & & 36.08 \\
\hline 5.0 & 41.762 & 41.844 & 41.474 & & 41.084 & & \\
\hline 5.4 & 42.284 & 42.360 & 41.995 & & & 49 & \\
\hline 6.0 & 42.738 & 42.807 & 42.451 & & & & 39.70 \\
\hline 6.6 & 42.908 & 42.971 & 42.623 & & 41.172 & & \\
\hline 8.0 & 42.611 & 42.662 & 42.333 & & & & 39.71 \\
\hline 10.0 & 41.335 & 41.373 & 41.072 & 38.00 & & 44 & 38.33 \\
\hline 10.81 & 40.689 & 40.724 & 40.433 & & 38.972 & & \\
\hline 15.0 & 37.106 & 37.126 & 36.877 & & & & 34.47 \\
\hline 15.64 & 36.570 & 36.588 & 36.346 & & 35.365 & & \\
\hline 20.0 & 33.183 & 33.194 & 32.984 & 33.10 & & 36 & 31.36 \\
\hline 23.78 & 30.655 & 30.662 & 30.473 & & 30.351 & & \\
\hline 25.0 & 29.915 & 29.921 & 29.738 & & & & 28.87 \\
\hline 30.0 & 27.221 & 27.222 & 27.061 & & & & 26.57 \\
\hline 38.6 & 23.592 & 23.591 & 23.457 & & 23.691 & & \\
\hline 40.0 & 23.096 & 23.094 & 22.963 & & & & 22.78 \\
\hline 50.0 & 20.105 & 20.101 & 19.991 & & & & 20.09 \\
\hline 60.0 & 17.839 & 17.835 & 17.739 & 17.50 & & 28 & \\
\hline 63.56 & 17.160 & 17.154 & 17.064 & & 17.410 & & \\
\hline 70.0 & 16.062 & 16.057 & 15.973 & & & & 16.35 \\
\hline 99.15 & 12.532 & 12.527 & 12.465 & & 12.765 & & \\
\hline 100.0 & 12.454 & 12.449 & 12.387 & 12.40 & & & 12.90 \\
\hline 149.4 & 9.207 & 9.202 & 9.160 & & 9.387 & & \\
\hline 150.0 & 9.179 & 9.174 & 9.131 & 9.63 & & & 9.60 \\
\hline 200.0 & 7.333 & 7.328 & 7.296 & 7.56 & & & 7.66 \\
\hline 249.9 & 6.139 & 6.135 & 6.110 & & 6.236 & & \\
\hline 300.0 & 5.296 & 5.292 & 5.271 & & & & 5.56 \\
\hline 400.0 & 4.183 & 4.179 & 4.164 & & & & 4.34 \\
\hline 400.5 & 4.178 & 4.175 & 4.160 & & 4.230 & & \\
\hline 600.0 & 2.982 & 2.979 & 2.970 & & & & 3.08 \\
\hline 601.4 & 2.976 & 2.973 & 2.965 & & 3.010 & & \\
\hline 800.0 & 2.337 & 2.335 & 2.330 & & & & 2.43 \\
\hline 802.3 & 2.332 & 2.330 & 2.324 & & 2.348 & & \\
\hline 1000.0 & 1.932 & 1.930 & 1.927 & & & & 2.01 \\
\hline 1404.2 & 1.442 & 1.441 & 1.440 & & 1.447 & & \\
\hline 2000.0 & 1.061 & 1.060 & 1.061 & & & & 1.08 \\
\hline
\end{tabular}

One can see that our results completely agree with the data from [10]. For the most of calculated energies, the deviations from the NIST database values are less than $0.5 \%$. For the HF+CI calculations, $M S D=0.55 \%$, and for the $\mathrm{QR}+\mathrm{CI}$ calculations, $M S D=0.66 \%$. Their agreement with the experimental data from [26-28] is fine, too. Some larger deviations appear at the electron energies lower than $3 \mathrm{eV}$. Deviations from the theoretical data [29] are more noticeable. The reason for this discrepancy is that the $B E, f$-reduction procedure has not been applied in [29].

A completely different situation is observed for the $2 s-3 p$ excitation by electron impact. The cross sections of this process are presented in Table 7. Our $\mathrm{HF}+\mathrm{CI}$ 
Table 7. The $2 s-3$ p electron-impact excitation cross sections $\sigma$ (in $10^{-17} \mathrm{~cm}^{2}$ ) for Li atom at various incident electron energies $\varepsilon$.

\begin{tabular}{|c|c|c|c|}
\hline$\varepsilon(\mathrm{eV})$ & $\mathrm{HF}+\mathrm{CI}$ & $\mathrm{QR}+\mathrm{CI}$ & $B E, f[10]$ \\
\hline 4 & 3.470 & 3.486 & 5.329 \\
\hline 5 & 6.313 & 6.317 & 9.753 \\
\hline 6 & 6.481 & 6.481 & 10.059 \\
\hline 7 & 6.256 & 6.254 & 9.740 \\
\hline 8 & 5.952 & 5.950 & 9.289 \\
\hline 9 & 5.647 & 5.645 & 8.826 \\
\hline 10 & 5.361 & 5.359 & 8.387 \\
\hline 15 & 4.258 & 4.256 & 6.667 \\
\hline 20 & 3.537 & 3.535 & 5.530 \\
\hline 30 & 2.656 & 2.655 & 4.137 \\
\hline 40 & 2.136 & 2.135 & 3.314 \\
\hline 60 & 1.545 & 1.544 & 2.382 \\
\hline 80 & 1.216 & 1.215 & 1.866 \\
\hline 100 & 1.005 & 1.004 & 1.536 \\
\hline 120 & 0.858 & 0.858 & 1.308 \\
\hline 140 & 0.750 & 0.749 & 1.139 \\
\hline 160 & 0.666 & 0.666 & 1.010 \\
\hline 180 & 0.600 & 0.600 & 0.908 \\
\hline 200 & 0.546 & 0.546 & 0.825 \\
\hline 250 & 0.446 & 0.446 & 0.672 \\
\hline 300 & 0.378 & 0.378 & 0.568 \\
\hline 400 & 0.291 & 0.291 & 0.434 \\
\hline 600 & 0.200 & 0.200 & 0.297 \\
\hline 800 & 0.153 & 0.153 & 0.227 \\
\hline 1000 & 0.125 & 0.124 & 0.184 \\
\hline 1500 & 0.085 & 0.085 & 0.125 \\
\hline 2000 & 0.065 & 0.065 & 0.095 \\
\hline 3000 & 0.044 & 0.044 & 0.065 \\
\hline
\end{tabular}

results agree with the $\mathrm{QR}+\mathrm{CI}$ results very well within all investigated electron energy range. Meanwhile, they are approximately by $34 \%$ smaller when compared to the data from [10]. It is important to notice that the $3 \mathrm{p}-2 \mathrm{~s}$ radiative transition probability $A$ values can change significantly depending on the composition of the radial orbital basis and the amount of admixed configurations. Our calculated values converge to the data presented in Table 5 only after the CI expansion basis is made very large. At the same time, the electronimpact excitation cross section values have been rather stable and practically have not changed following the increase of the wavefunction basis, after all the most important admixed configurations have been included.

We do not apply the $f$-reduction (12) for our data because the difference between our radiative transition probabilities and the data from [10] is only 6\%, and the transition energies agree really well. Therefore, that reduction cannot alter significantly our calculated

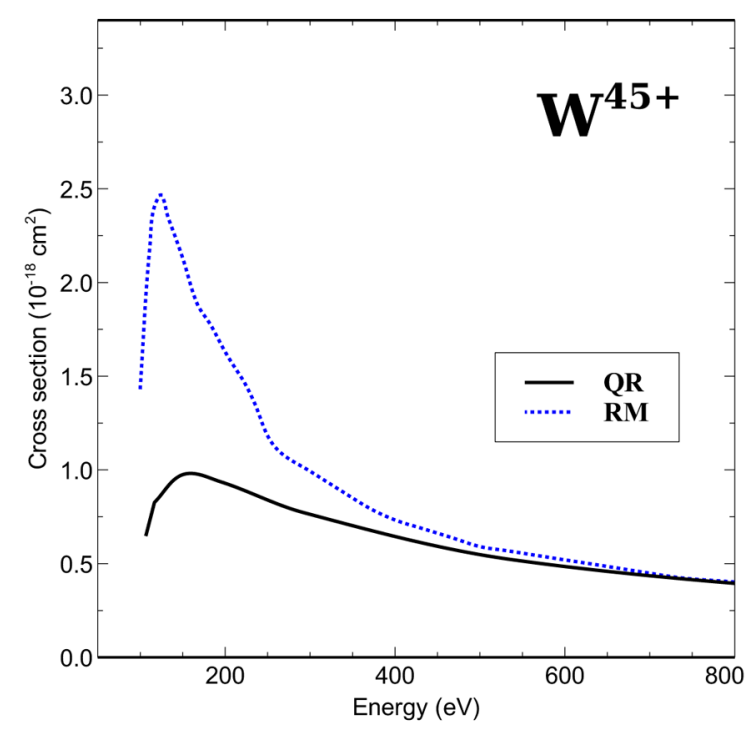

Fig. 1. Comparison of the $\mathrm{W}^{45+}$ electron-impact excitation cross sections from the ground state to the $4 \mathrm{p}^{2} \mathrm{P}_{1 / 2}$ level. The dotted curve is the R-matrix (RM) damped cross section convoluted with a $30 \mathrm{eV}$ Gaussian from [30], the solid curve represents our quasirelativistic (QR) calculation.

electron-impact excitation cross section values. The overestimated cross section $\sigma_{B E, f}$ values in [10] can be a consequence of the $f$-scaling procedure applied in that work. This is caused by the situation where the E1 transition probability is proportional to the matrix element of the $\left\langle r^{1}\right\rangle$ operator which is more important at longer distances. Meanwhile, when calculating the electronimpact excitation cross sections, one needs to apply the $\left\langle f_{1}(q r)\right\rangle$ operator which has a maximum located closer to a nucleus.

Unfortunately, we could not find any additional references on the experimental data or the calculation results of the $2 s-3 p$ excitation of $\mathrm{Li}$ atoms.

\subsection{Excitation of tungsten ions}

Previous comparisons for $\mathrm{H}, \mathrm{He}$, and $\mathrm{Li}$ demonstrate that the applied method is able to produce good-quality results for light neutral atoms. Described computer codes are mainly targeted for the production of electron scattering parameters for substantially more complex many-electron ions where it is very difficult to apply more accurate approximations and calculation methods developed for the electron-ion collision processes. In such a case, it is not a simple task even to determine correct and inclusive-enough CI wavefunction expansion for the considered target system. The problems increase even more when one has to consider the target+electron system containing significantly 


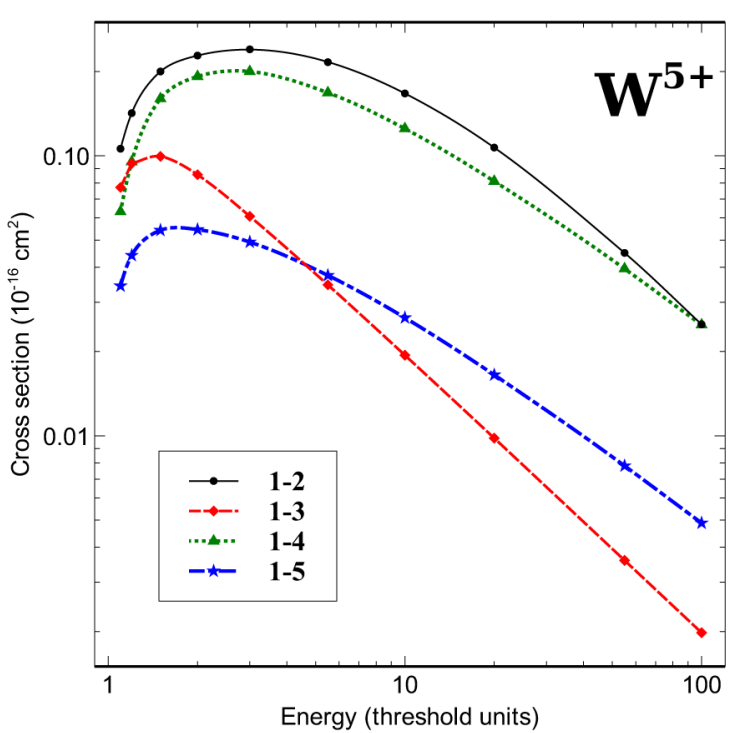

Fig. 2. Electron-impact excitation cross sections (in $10^{-16} \mathrm{~cm}^{2}$ ) from the ground state $5 \mathrm{p}^{6} 5 \mathrm{~d}^{2} \mathrm{D}_{3 / 2}$ of the $\mathrm{W}^{5+}$ ion to the excited states $5 p^{6} 5 d^{2} D_{5 / 2}$ (solid curve), $5 p^{6} 6 s^{2} S_{1 / 2}$ (dashed curve), $5 \mathrm{p}^{6} 6 \mathrm{p}^{2} \mathrm{P}_{1 / 2}$ (dotted curve), and $5 \mathrm{p}^{6} 6 \mathrm{p}^{2} \mathrm{P}_{3 / 2}$ (dash-dotted curve). Incident electron energies are given in transition threshold units. $X=E / \Delta E$.

more configurations. This is the main reason why there are not so many data determined in R-matrix or CCC approach for heavy ions. Therefore, application of a rather simple approximation, such as plane-wave Born, for the scattering process description becomes

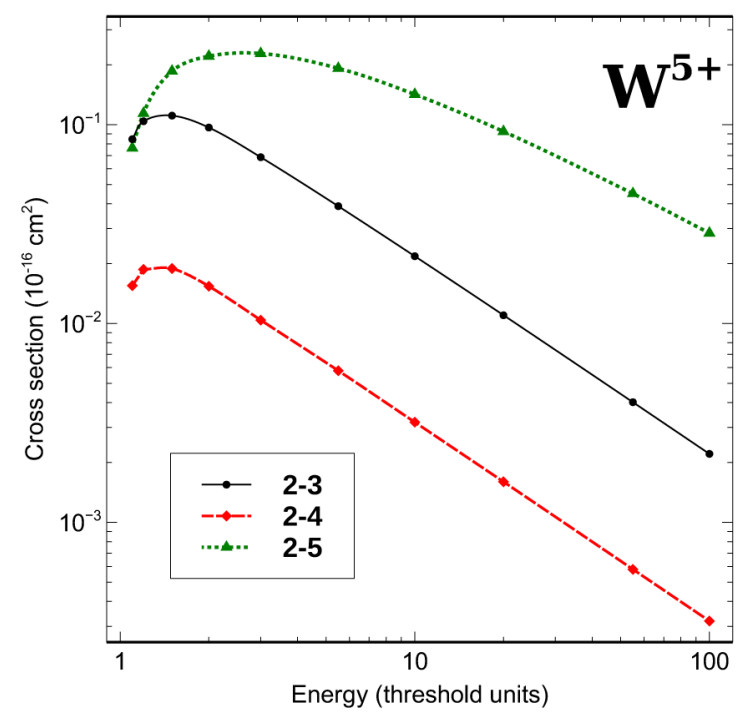

Fig. 3. Electron-impact excitation cross sections (in $10^{-16} \mathrm{~cm}^{2}$ ) from the first excited state $5 \mathrm{p}^{6} 5 \mathrm{~d}^{2} \mathrm{D}_{5 / 2}$ of the $\mathrm{W}^{5+}$ ion to the excited states $5 \mathrm{p}^{6} 6 \mathrm{~s}{ }^{2} \mathrm{~S}_{1 / 2}$ (solid curve), ${ }^{5} p^{6} 6 p{ }^{2} \mathrm{P}_{1 / 2}$ (dashed curve), and $5 p^{6} 6 p^{2} \mathrm{P}_{3 / 2}$ (dotted curve). Incident electron energies are given in transition threshold units. the most optimal, if not the only possible way so far to determine necessary data.

There are just a few data sources of collision data for complex many-electron tungsten ions. In [30] the results of fully relativistic, radiatively damped $\mathrm{R}$ matrix calculations for $\mathrm{W}^{44+}$ and $\mathrm{W}^{45+}$ are presented. The authors in [30] were able to perform such kind of scattering calculations for these ions because of a relatively small number of levels in the target expansion. We compare data from [30] to our calculation for the $\mathrm{W}^{45+}$ in Fig. 1. The threshold energy for this transition $\Delta E=97.275 \mathrm{eV}$ agrees very well with data from [30] where $\Delta E=97.233 \mathrm{eV}$. Similarly, the radiative transition probability in [30] $A=5.07 \times 10^{10} \mathrm{~s}^{-1}$ is very close to our determined value of $A=5.04 \times 10^{10} \mathrm{~s}^{-1}$ (the deviation is just $0.6 \%$ ).

One can clearly see two different trends in that comparison. At the higher-energy end $(E>300 \mathrm{eV})$, the deviations are reasonably small, and they differ just by a few percent when the incident electron energy is above $800 \mathrm{eV}$. At the low incoming electron energies $(E<300 \mathrm{eV})$, the difference between our data and $\mathrm{R}$-matrix values is significant. The R-matrix calculation data are some 2.5 times larger than our cross section values at $E=125 \mathrm{eV}$, where cross sections reach maximum values. But that difference falls sharply when the incident electron energy increases. There are two main reasons for such a behaviour. The R-matrix electron-impact excitation cross-section contains abundance of resonances which reflect excitation through autoionizing levels of the $\mathrm{W}^{44+}$ ion. These resonances are located near the excitation threshold; therefore, they can make up $20-25 \%$ of the convoluted cross section value, as one can see from Fig. 4 in [30]. Another reason is that there is a strong interaction between incident free electron and the bound electrons of the $\mathrm{W}^{45+}$ ion. This interaction cannot be included in the plane-wave approximation adopted in the current work. Such an omission leads to smaller cross section values in our calculation. It is necessary to underline that quite a large electron energy range is required when collision rates are determined. That leads to a rather small difference (especially at higher temperatures) in determined rate values applied in high-temperature plasma modelling.

Even more complicated calculations are required when low ionization stages of tungsten ions are investigated. We have performed electron-impact excitation cross section calculations for several isoelectronic sequences such as Tm-, Yb-, Lu-, Hf-like ions including $\mathrm{W}^{2+}-\mathrm{W}^{5+}$ ions. Data for these ions are important in fusion plasma spectra modelling. We have determined both the spectroscopic parameters (energy levels, transition wavelengths, radiative transition probabilities) 


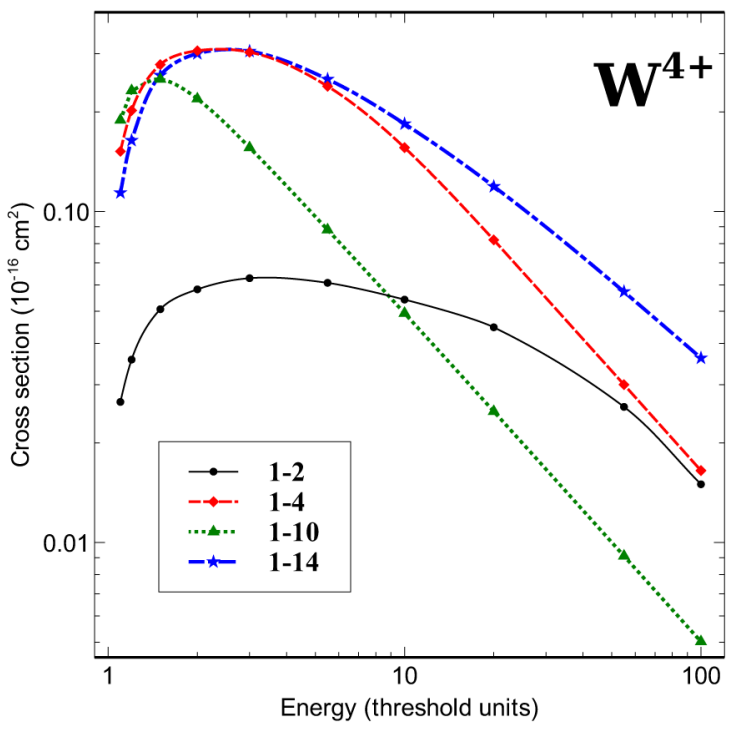

Fig. 4. Electron-impact excitation cross sections (in $10^{-16} \mathrm{~cm}^{2}$ ) from the ground state $5 \mathrm{p}^{6} 5 \mathrm{~d}^{2}{ }^{3} \mathrm{~F}_{2}$ of the $\mathrm{W}^{4+}$ ion to the excited states $5 \mathrm{p}^{6} 5 \mathrm{~d}^{2}{ }^{3} \mathrm{~F}_{3}$ (solid curve), $5 \mathrm{p}^{6} 5 \mathrm{~d}^{2}{ }^{3} \mathrm{P}_{0}$ (dashed curve), $5 \mathrm{p}^{6} 5 \mathrm{~d} 6 \mathrm{~s}^{3} \mathrm{D}_{1}$ (dotted curve), and $5 \mathrm{p}^{6} 5 \mathrm{~d} 6 \mathrm{p}^{3} \mathrm{~F}_{2}$ (dash-dotted curve). Incident electron energies are given in transition threshold units.

and the electron-impact excitation parameters (collision strengths, cross sections, collision rates) for several ions of these sequences. Our data are incorporated in Atomic Data and Analysis System (ADAS) [3] as the

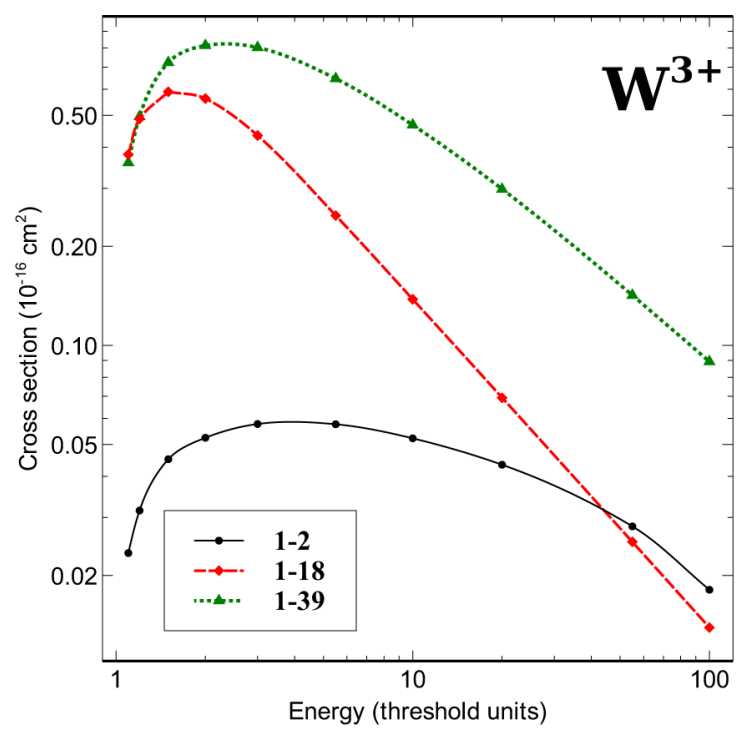

Fig. 5. Electron-impact excitation cross sections (in $10^{-16} \mathrm{~cm}^{2}$ ) from the ground state $5 \mathrm{p}^{6} 5 \mathrm{~d}^{3}{ }^{4} \mathrm{~F}_{3 / 2}$ of the $\mathrm{W}^{2+}$ ion to the excited states $5 \mathrm{p}^{6} 5 \mathrm{~d}^{3}{ }^{4} \mathrm{~F}_{5 / 2}$ (solid curve), $5 p^{6} 5 d^{2} 6 s^{4} F_{3 / 2}$ (dashed curve), and $5 p^{6} 5 d^{2} 6 p^{4} F_{3 / 2}$ (dotted curve). Incident electron energies are given in transition threshold units. basic parameters and are utilized to determine the derived parameters for various plasma conditions.

To demonstrate the abilities of our developed computer codes, we present several plots of the electronimpact excitation cross sections for the tungsten ions ranging from $\mathrm{W}^{5+}$ to $\mathrm{W}^{2+}$. Our performed calculation involves a large number of excitations involving levels of these ions. All possible excitation transitions involving several hundreds of levels are considered. Plots given in the present paper are given for demonstration purpose.

Figures 2 and 3 demonstrate cross sections for the $\mathrm{W}^{5+}$ ion excitation from the ground and from the first excited level. For other three ions, namely $\mathrm{W}^{4+}, \mathrm{W}^{3+}$, and $\mathrm{W}^{2+}$, we present only the excitation parameters from the ground level in Figs. 4 6, although much more data are produced. For example, we consider the lowest 293 levels in $\mathrm{W}^{2+}$ and transitions among them.

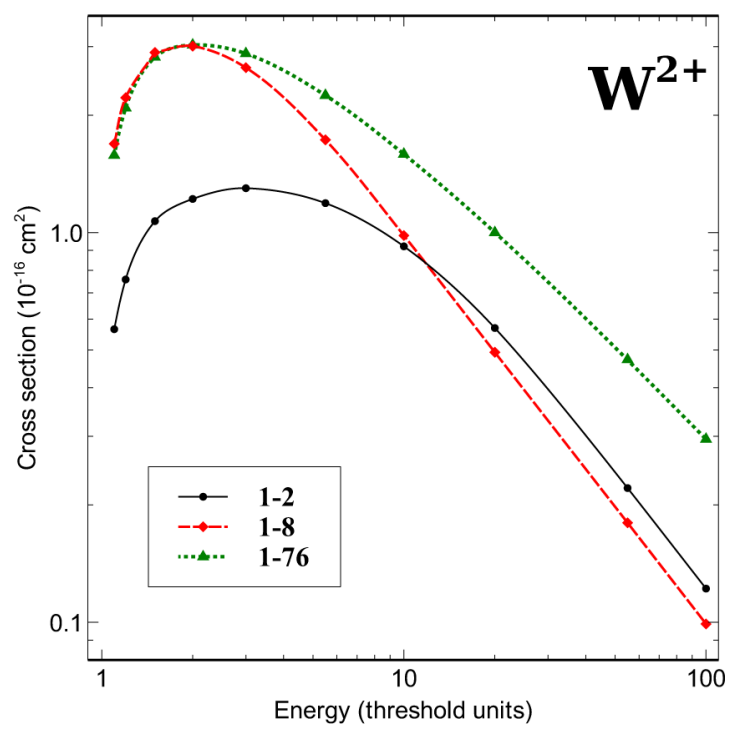

Fig. 6. Electron-impact excitation cross sections (in $10^{-16} \mathrm{~cm}^{2}$ ) from the ground state $5 \mathrm{p}^{6} 5 \mathrm{~d}^{45} \mathrm{D}_{0}$ of the $\mathrm{W}^{2+}$ ion to the excited states $5 p^{6} 5 d^{4}{ }^{5} D_{1}$ (solid curve), $5 p^{6} 5 d^{3} 6 s^{5} F_{2}$ (dashed curve), and $5 \mathrm{p}^{6} 5 \mathrm{~d}^{3} 6 \mathrm{p}^{3} \mathrm{D}_{1}$ (dotted curve). Incident electron energies are given in transition threshold units.

\section{Summary and conclusions}

The performed calculations of the electron-impact excitation data and their analysis have demonstrated that the computational methods implemented in our newly developed computer codes are suitable to produce the electron-impact excitation cross sections and related parameters, such as the electron-impact collision strengths or collision rates. One can expect that such data for other ions will be reliable enough.

Based on good agreement of the radiative transition probabilities with existing data, we expect that 
our determined electron-impact excitation cross sections for the $2 s-3 p$ transition in the Li atom are accurate enough. The comparison of cross sections for $\mathrm{W}^{45+}$ leads to a conclusion that the calculated parameters even for highly charged ions can be applied in hightemperature fusion plasma spectra modelling. Significant deviations from earlier published results can be explained by the fact that radiative transition partameters are influenced by inclusion of correlation corrections differently compared to excitation cross sections. Therefore, a simple normalization described by Eq. (12) in [10] is not well-grounded.

We are planning to incorporate results of such calculations (together with other spectroscopic parameters) into the newly developed database ADAMANT when the electron-impact excitation processes in various many-electron atoms and ions with open s-, p-, d-, and f- shells are considered.

\section{Acknowledgements}

D. S. acknowledges support by the project "Promotion of Student Scientific Activities" (VP1-3.1-ŠMM01-V-02-003) from the Research Council of Lithuania, funded by the Republic of Lithuania and European Social Fund under the 2007-2013 Human Resources Development Operational Programme's priority 3. P. B. and R. K. acknowledge the support by NSF grant AST/1109061.

\section{References}

[1] P. Bogdanovich, Multiconfiguration approach in the study of atomic spectra, Lith. J. Phys. 44(2), 135-153 (2004), http://dx.doi.org/10.3952/lithjphys.44204

[2] P. Bogdanovich, Modern methods of multiconfiguration studies of many-electron highly charged ions, Nucl. Instrum. Methods B 235(14), 92-99 (2005), http://dx.doi.org/10.1016/j. nimb.2005.03.152

[3] H.P. Summers, The ADAS User Manual, version 2.6 (2004), http://www.adas.ac.uk

[4] A. Kramida, Yu. Ralchenko, J. Reader, and NIST ASD Team, NIST Atomic Spectra Database, version 5.1 (National Institute of Standards and Technology, Gaithersburg, MD, USA, 2013), http://physics.nist.gov/asd

[5] Y.-K. Kim, K.K. Irikura, M.E. Rudd, M.A. Ali, P.M. Stone, J. Chang, J.S. Coursey, R.A. Dragoset, A.R. Kishore, K.J. Olsen, A.M. Sansonetti, G.G. Wiersma, D.S. Zucker, and M.A. Zucker, Electron-impact Ionization Cross Section for Ionization and Excitation Database, version 3.0 (National Institute of Standards and Technology, Gaithersburg, MD, USA, 2004), http://physics. nist.gov/ionxsed
[6] I. Bray and Yu. Ralchenko, The CCC Data Base (online) (2001), http://atom.curtin.edu.au/CCCWWW

[7] C.F. Fischer, M.R. Godefroid, and A. Hibbert, A program for performing angular integrations for transition operators, Comput. Phys. Commun. 64(3), 486-500 (1991), http://dx.doi. org/10.1016/0010-4655(91)90140-G

[8] M. Abramovitz and I.A. Stegun, eds. Handbook of Mathematical Functions, Vol. 55 Applied Mathematics Series National Bureau of Standards, Gaithersburg, MD, USA, 1964 pp. 355-490.

[9] G.A. Korn and T.M. Korn, Mathematical Handbook for Scientists and Engineers (New-York, Toronto, London: McGraw \& Hill Book Company, Inc, 1961).

[10] P.M. Stone, Y.-K. Kim, and J.P. Desclaux, Electronimpact cross sections for dipole- and spin-allowed excitations of hydrogen, helium, and lithium, J. Res. Natl. Inst. Stand. Technol. 107(4), 327-338 (2002), http://dx.doi.org/10.6028/jres.107.026

[11] Y.-K. Kim, Scaling of plane-wave Born cross sections for electron-impact excitation of neutral atoms, Phys. Rev. A 64(3), 032713 (2001), http:// dx.doi.org/10.1103/PhysRevA.64.032713

[12] A. Grafe, C.J. Sweeney, and T.W. Shyn, Measurement of absolute differential cross sections for the excitation of atomic hydrogen to its $n=2$ level by electron impact, Phys. Rev. A 63(5), 052715 (2001), http://dx.doi.org/10.1103/PhysRevA.63.052715

[13] P. Bogdanovich and R. Karpuškiené, Transformed radial orbitals with a variable parameter for the configuration interaction, Lith. J. Phys. 39(3), 193208 (1999).

[14]P. Bogdanovich and R. Karpuškienè, Numerical methods of the preliminary evaluation of the role of admixed configurations in atomic calculations, Comp. Phys. Comm. 134(3), 321-334 (2001), http://dx.doi.org/10.1016/S0010-4655(00)00214-9

[15] P. Bogdanovich, D. Majus, and T. Pakhomova, Investigation of accuracy of configuration interaction for the oxygen isoelectronic sequence, Phys. Scr. 74(5), 558-562 (2006), http://dx.doi. org/10.1088/0031-8949/74/5/013

[16] P. Bogdanovich and O. Rancova, Quasirelativistic Hartree-Fock equations consistent with BreitPauli approach, Phys. Rev. A 74(5), 052501 (2006), http://dx.doi.org/10.1103/PhysRevA.76.012507

[17] P. Bogdanovich and O. Rancova, Adjustment of the quasirelativistic equations for $p$ electrons, Phys. Rev. A 76(1), 012507 (2007), http://dx.doi. org/10.1103/PhysRevA.76.012507

[18] P. Bogdanovich and O. Rancova, Quasirelativistic approach for ab initio study of highly charged ions, Phys. Scr. 78(4), 045301 (2008), http://dx.doi. org/10.1088/0031-8949/78/04/045301

[19] D.C. Morton, Q. Wu, and G.W.F. Drake, Energy levels for the stable isotopes of atomic helium $\left({ }^{4} \mathrm{He}\right.$ I 
and ${ }^{3} \mathrm{He}$ I), Can. J. Phys. 84, 83-105 (2006), http:// dx.doi.org/10.1139/p06-009

[20] W.L. Wiese and J.R. Fuhr, Accurate atomic transition probabilities for hydrogen, helium, and lithium, J. Phys. Chem. Ref. Data 38(3), 565-720 (2009), http://dx.doi.org/10.1063/1.3077727 Erratum: J. Phys. Chem. Ref. Data 38(4), 1129 (2009), http://dx.doi.org/10.1063/1.3254213

[21]H. Merabet, M. Bailey, R. Bruch, J. Hanni, S. Bliman, D.V. Fursa, I. Bray, K. Bartschat, H.C. Tang, and C.D. Lin, Cross sections and collision dynamics of the excitation of $(1 s n \mathrm{p}){ }^{1} \mathrm{P}^{o}$ levels of helium, $n=2-5$, by intermediate- and high-velocity electron, proton, and molecular-ion $\left(\mathrm{H}_{2}^{+}\right.$and $\mathrm{H}_{2}^{+}$) impact, Phys. Rev. A 64(1), 012712 (2001), http://dx.doi.org/10.1103/PhysRevA.64.012712

[22] W.B. Westerveld, H.G.M. Heideman, and J. van Eck, Electron impact excitation of $1^{1} \mathrm{~S} \rightarrow 2^{1} \mathrm{P}$ and $1^{1} \mathrm{~S} \rightarrow 3^{1} \mathrm{P}$ of helium: excitation cross sections and polarisation fractions obtained from XUV radiation, J. Phys. B: At. Mol. Phys. 12(1), 115-136 (1979), http://dx.doi.org/10.1088/0022-3700/12/1/019

[23]D.E. Shemansky, D.T. Hall, J.M. Ajello, and B. Franklin, Vacuum ultraviolet studies of electron impact of helium excitation of He $n^{1} \mathrm{P}^{\circ}$ Rydberg series and ionization-excitation of $\mathrm{He}^{+} n l$ Rydberg series, Astrophys. J. 296, 774-783 (1985), http:// dx.doi.org/10.1086/163494

[24] S. Trajmar, J.M. Ratliff, G. Csanak, and D.C. Cartwright, Proposed standard inelastic differential electron scattering cross sections; excitation of the
$2^{1} \mathrm{P}$ level in He, Z. Phys. D 22(2), 457-462 (1992), http://dx.doi.org/10.1007/BF01426087

[25] F.J. de Heer, Critically Assessed Electron-impact Excitation Cross Sections for $\mathrm{He}\left(1^{1} \mathrm{~S}\right)$, International Nuclear Data Committee Report IDNC(NDS)-385 (Vienna, Austria, 1998), https://www-nds.iaea. org/publications/indc/indc-nds-0385/

[26] L. Vuskovic, S. Trajmar, and D.F. Register, Electron impact cross sections for the $2^{2} \mathrm{P}$ state excitation of lithium, J. Phys. B 15(15), 2517-2530 (1982), http://dx.doi.org/10.1088/0022-3700/15/15/024

[27] D. Leep and A. Gallagher, Electron excitation of the lithium $6708 \AA$ resonance line, Phys. Rev. A 10(4), 1082-1090 (1974), http://dx.doi.org/10.1103/ PhysRevA.10.1082

[28] W. Williams, S. Trajmar, and D. Bozinis, Electron scattering from Li at 5.4, 10, 20 and $60 \mathrm{eV}$ impact energies, J. Phys. B: At. Mol. Phys. 9(9), 15291536 (1976), http://dx.doi.org/10.1088/0022$3700 / 9 / 9 / 018$

[29] J.Schweinzer, R. Brandenburg, I. Bray, R. Hoekstra, F. Aumayr, R.K. Janev, and H.P. Winter, Database for inelastic collisions of lithium atoms with electrons, protons, and multiply charged ions, Atomic Data Nucl. Data Tables 72(2), 239-273 (1999), http://dx.doi.org/10.1006/adnd.1999.0815

[30] C.P. Ballance and D.C. Griffin, Electron-impact excitation of $\mathrm{W}^{44+}$ and $\mathrm{W}^{45+}$, J. Phys. B: 40(2), 247-258 (2007), http://dx.doi.org/10.1088/0953-4075/40/2/001

\title{
METODAI, ALGORITMAI IR KOMPIUTERINĖS PROGRAMOS ATOMŲ SUŽADINIMO ELEKTRONAIS PARAMETRAMS SKAIČIUOTI
}

\author{
P. Bogdanovičius, R. Kisielius, D. Stonys \\ Vilniaus universiteto Teorines fizikos ir astronomijos institutas, Vilnius, Lietuva
}

\begin{abstract}
Santrauka
Aprašome Vilniaus universiteto Teorinès fizikos ir astronomijos instituto Atomo teorijos skyriuje sukurtas kompiuterines programas, skirtas skaičiuoti atomų ir jonų sužadinimo elektronų smūgiais skerspjūvius, smūgių stiprius ir sužadinimo greičius plokščiųjų bangų pirmajame Borno artinyje. Sios programos naudoja daugiakonfigūracines daugiatermes atomo bangines funkcijas; tos pačios banginès funkcijos yra pritaikomos sudetingų daugiaelektronių jonų radiacinių šuolių parametrams (šuolių bangų ilgiams, šuolių osciliatorių stipriams, šuolių tikimybėms) skaičiuoti. Tokiu būdu imanoma gauti patikimus duomenis, tinkamus plazmų modeliavimo programoms.
\end{abstract}

Šiame darbe tiriame dvi skirtingas elektronų sklaidos programas, tačiau jos abi naudoja konfigūracijų sąveikos metodą koreliaciniams efektams įskaityti bei Breito ir Paulio artinị, leidžiantị îvertinti reliatyvistinius efektus. Šios dvi programos skiriasi tik vienelektronèmis radialiosiomis orbitalèmis; pirmoji programa naudoja nereliatyvistines skaitines radialiąsias orbitales, o antroji - kvazireliatyvistines radialiąsias orbitales. Mūsų duomenų tikslumą ịvertiname palygindami juos su kitų autorių neutralių vandenilio, helio ir ličio atomų bei daugiakrūvių volframo jonų radiacinių šuolių ir sužadinimo elektronų smūgiais teoriniais rezultatais bei eksperimentiniais duomenimis. 